\title{
PARTISIPASI PEDAGANG KAKI LIMA DALAM PENGELOLAAN SAMPAH DI PASAR BAWAH KOTA BUKITTINGGI
}

\author{
Mentari $^{1}$, Yurni Suasti ${ }^{2}$, Fitriana Syahar ${ }^{2}$ \\ Program Studi Pendidikan Geografi, \\ Fakultas Ilmu Sosial, Universitas Negeri Padang \\ Email: mtari2607@gmail.com
}

\begin{abstract}
Abstrak
Penelitian ini bertujuan untuk mengetahui tingkat partisipasi pedagang kaki lima dalam pengelolaan sampah Pasar Bawah Kota Bukittinggi yang terletak di kecamatan Guguak Panjang Kota Bukittinggi. Jenis penelitian menggunakan metode deskriptif kuantitatif yang dilaksanakan selama 3 bulan. Populasi dalam penelitian ini seluruh pedagang kaki lima yang berjualan di Pasar Bawah Kota Bukittinggi berjumlah 577 orang. Teknik sampel menggunakan Random sampling dengan rumus slovin dan jumlah sampel 85 pedagang kaki lima. Alat pengumpul data yang digunakan adalah angket dan data diolah menggunakan formula persentase. Berdasarkan hasil analisis deskriptif maka dapat diketahui tingkat partisipasi pedagang kaki dalam pengelolaan sampah di Pasar Bawah Kota Bukittinggi tergolong baik dengan skor keseluruhan yang di dapat yaitu 1910. Bentuk partisipasi tertinggi yaitu partisipasi membayar retribusi sampah dengan persentse $12,77 \%$.
\end{abstract}

Kata Kunci : Partisipasi, Pedagang kaki lima, Pengelolaan Sampah

\begin{abstract}
This study aims to determine the level of participation of street vendors in waste management in Pasar Bawah Bukittinggi city which located in Guguak Panjang Sub-district, Bukittinggi city. This type of research uses quantitative descriptive method which is carried out for 3 months. The population in this study all the street vendors selling in the Pasar Bawah of Bukittinggi City totaled 577 people. The sample tecnique uses Random Sampling with Slovin formula and the number of samples is 85 street vendors. Data collection tools used are questionnaires and data processed using percentage formulas. Based on the results of the descriptive analysis, it can be seen that the participation level of street vendors in the Pasar Bawah management of Bukittinggi is classified as good with an overall score of 1910. The highest form of participation is participation in paying waste retribution with a percentage of $12,77 \%$.
\end{abstract}

Keywords : participation, street vendors, waste management

\footnotetext{
${ }^{1}$ Mahasiswa Program Studi Pendidikan Geografi

${ }^{2}$ Dosen Jurusan Geografi Fakultas Ilmu Sosial Universitas Negeri Padang dengan Pembimbing I Dra. Yurni Suasti, M.Si dan Pembimbing II Fitriana syahar, S.Si. M.Si.
} 


\section{PENDAHULUAN}

Partisipasi sangat diperlukan dalam kelancaran suatu pembangunan. Salah satu indikator dalam pembangunan adalah kebersihan. Dalam menjaga kebersihan terutama untuk kebersihan pasar, pedagang memiliki andil besar. Salah satunya pedagang kaki lima.

Partisipasi menurut djalal dkk (2001) adalah pembuat keputusan, menyarankan kelompok atau masyarakat ikut terlibat dalam bentuk penyampaian saran atau pendapat, barang, keterampilan, bahan dan jasa. Partisipasi dapat juga berarti bahwa kelompok mengenal masalah mereka sendiri, mengkaji pilihan mereka, membuat keputusan, dan memecahkan masalahnya.

Tilaar (2009) mengungkapkan partisipasi adalah sebagai wujud dari keinginan untuk mengembangkan demokrasi melalui proses desentralisasi dimana diupayakan antara lain perlunya perencanaan dari bawah (bottom-up) dengan mengikutsertakan masyarakat dalam proses perencanaan dan pembangunan masyarakatnya.

Pedagang Kaki Lima (PKL) merupakan bagian dari salah satu jenis usaha sektor informal yang meliputi berbagai jenis usaha antara lain pembantu rumah tangga, ojek, pedagang keliling dan lain-lain. Pengertian Pedagang Kaki Lima (PKL) berasal dari zaman Raffles yaitu "5 (five) feets" yang berarti jalur pejalan kaki dipinggir jalan selebar lima kaki dikemukakan oleh Manning dalam Sumarwanto (2012).
Dari pengertian atau batasan tentang pedagang kaki lima sebagaimana dikemukakan beberapa ahli di atas, dapat dipahami bahwa pedagang kaki lima merupakan bagian dari kelompok usaha kecil yang bergerak di sektor informal. Secara khusus, pedagang kaki lima dapat diartikan sebagai distribusi barang dan jasa yang belum memiliki izin usaha dan biasanya berpindah-pindah.

Dalam menjaga kebersihan pasar dibutuhkan partisipasi aktif dari pedagang, khususnya pedagang kaki lima yang mempunyai tempat tidak tetap. Partisipasi akan berdampak baik sehingga membuat lingkungan pasar tersebut menjadi bersih dan bebas dari sampah.

Bukittinggi merupakan salah satu kota pariwisata yang ada di Sumatera Barat. Dimana rata-rata tiap tahunnya banyak pengunjung yang datang dari berbagai daerah untuk berwisata ataupun berbelanja ke kota ini. Bukittinggi juga merupakan salah satu kota yang mendapatkan penghargaan Adiwiyata di tahun 2017 sebagai salah satu kota yang dinilai berhasil dalam menjaga lingkungan hidupnya. Bukittinggi mempunyai 3 pasar utama yaitu pasar aur kuning, pasar atas dan pasar bawah yang menjual berbagai kebutuhan, ada yang menjual pakaian, sandang dan pangan.

Pasar Bawah Kota Bukittinggi merupakan pasar yang rata-rata pedagangnya berjualan sayuran, buahbuahan dan jualan muda lainnya. Di pasar ini banyak terdapat pedagang kaki lima (PKL). PKL yang berjualan di Pasar ini pada hari pasar (Rabu/Sabtu) 
sekitar 557 PKL dan pada hari biasa sekitar 288 PKL. Para PKL ini berjualan dari jam 6 pagi sampai jam 6 sore. Setelah mereka berjualan pada sore hari masih banyak sampah yang tercecer dan tertinggal di tempat mereka berdagang. Sampah yang tertinggal ini menyebabkan lingkungan menjadi kotor, seperti yang kita ketahui Bukittinggi adalah salah satu kota yang mendapat penghargaan Adiwiyata, adiwiyata yang diperoleh merupakan kolaborasianatara pedagang kaki lima dan Dinas Lingkungan Hidup. Oleh karena itu sangat disayangkan apabila masyaraktnya kurang berpartisipasi di dalam kebersihan lingkungan hidup. Pasar bawah yang masih dipenuhi sampah yang bertebaran membuat lingkungan menjadi tidak bersih. Karena pedagangnya hanya mengandalkan petugas kebersihan yang akan membersihkan lingkungan pasar. Oleh karena itu dibutuhkan partisipasi dari para PKL agar lingkungan pasar menjadi lebih bersih lagi, baik itu partisipasi berupa gagasan, tindakan atau partisipasi dalam bentuk lainnya dalam pengelolaan sampah. Pengelolaan sampah adalah proses mengolah sampah dari mengumpulkan sampah, sampai dengan pembuangan sampah akhir.

Pengelolaan sampah di Kota Bukittinggi dilakukan oleh Dinas Lingkungan Hidup (DLH) yang bertanggung jawab atas kebersihan lingkungan kota. Walaupun sudah ada DLH, pengelolaan sampah masih mengharapkan partisipasi dari PKL baik secara langsung ataupun tidak langsung. Dalam pengelolaan sampah diharapkan ada partisipasi dari PKL hingga tahapan pengumpulan dan pembuangan sampah ke tempat pembuangan sampah sementara (TPS). Pengumpulan sampah yang dilakukan oleh DLH bersama PKL akan membuat lingkungan pasar menjadi lebih bersih. Kemudian sampah itu di angkut ke tempat pembuangan sampah akhir (TPA) dan menjadi tanggung jawab Dinas lingkungan hidup. Kerja sama yang baik antara PKL dengan DLH dapat membuat lingkungan pasar menjadi bersih, terhindar dari banyaknya bibit penyakit, polusi udara yang menjadikan kawasan pasar bau dan tidak nyaman. Namun jika PKL tidak berpartisipasi dan semua urusan pengelolaan sampah diserahkan pada DLH akan mengakibatkan banyaknya sampah tertinggal dan membuat lingkungan pasar tidak bersih dan berbau. Hal tersebut dapat merugikan pedagang karena pembeli tidak tahan berlama-lama di pasar akibat bau dan bisa menjadi sarang penyakit. Sesuai dengan permasalahan diatas peneliti ingin mengetahui bagaimana partisipasi pedagang kaki lima dalam pengelolaan sampah di Pasar Bawah Kota Bukittinggi. Dalam penelitian ini diharapkan akan memperoleh kesimpulan apakah pedagang kaki lima tersebut berpartisipasi dalam pengelolaan sampah. Pemikiran ini yang kemudian melatarbelakangi penelitian ini.

\section{METODE PENELITIAN}

Penelitian ini merupakan penelitian deskriptif kuantitatif. Dalam penelitian ini populasinya adalah semua pedagang kaki lima yang berjualan di Pasar Bawah Kota Bukittinggi dengan 
total 577 pedagang kaki lima. Teknik pengambilan sampel dalam penelitian ini adalah Random Sampling dengan jumlah sampel 85 pedagang kaki lima.

Teknik pengumpulan data pada penelitian ini menggunakan observasi, angket atau kuisioner, wawancara dan dokumentasi.

Instrumen penelitian menggunakan daftar pertanyaan atau kuisioner. Teknik analisis data menggunakan rumus persentase yaitu :

$$
\boldsymbol{p}=\frac{\mathbf{f}}{\boldsymbol{n}} \times 100 \%
$$

Dan memakai kriteria persentase dari Arikunto (2008).

\section{HASIL DAN PEMBAHASAN Partisipasi Memiliki Tempat Sampah Sendiri}

Tempat sampah adalah salah satu alat yang digunakan untuk mengumpulkan sampah. Partisipasi memiliki tempat sampah sendiri artinya pedagang kaki lima (PKL) memiliki tempat sampah sendiri seperti tong sampah kecil dan sebagainya.

Tabel 1. Persentase partisipasi pedagang kaki lima memiliki tempat sampah sendiri

\begin{tabular}{|c|l|c|c|c|c|}
\hline No. & \multicolumn{1}{|c|}{ Tingkat Partisipasi } & $\begin{array}{c}\text { Alternatif } \\
\text { skor }\end{array}$ & $\begin{array}{c}\text { Jumlah } \\
\text { Pedagang } \\
\text { kaki lima } \\
\text { (orang) }\end{array}$ & $\begin{array}{c}\text { Persentase } \\
(\%)\end{array}$ & $\begin{array}{c}\text { Total } \\
\text { skor }\end{array}$ \\
\hline 1 & $\begin{array}{l}\text { Punya tempat sampah } \\
\text { sendiri }\end{array}$ & 3 & 8 & 9,41 & 24 \\
\hline 2 & $\begin{array}{l}\text { Membuangnya ke } \\
\text { dalam kantong plastik }\end{array}$ & 2 & 60 & 70,59 & 120 \\
\hline 3 & $\begin{array}{l}\text { Tidak punya tempat } \\
\text { sampah senidiri }\end{array}$ & 1 & 17 & 20,00 & 17 \\
\hline \multicolumn{2}{|c|}{ Jumlah } & 85 & 100 & 161 \\
\hline
\end{tabular}

Sumber: Data Primer (2018)

\section{Partisipasi Membayar Retribusi Sampah}

Retribusi sampah adalah suatu biaya yang dibayarkan kepada pengelola pasar untuk biaya kebersihan pasar. Retribusi di bayar setiap hari oleh pedagang kaki lima (PKL) kepada petugas pasar. Partisipasi membayar retribusi sampah artinya apakah PKL membayar kewajibannya setiap berdagang atau tidak atau apakah PKL membayar retribusi sampah sesuai dengan aturan yang ditetapkan. Disini setiap pedagang membayar retribusi berdasarkan luas tempat berjualan yang permeternya

berkewajibannya membayar Rp.1500 per hari. Dapat dilihat pada tabel 2 . 
Tabel 2. Persentase partisipasi pedagang kaki lima membayar retribusi sampah

\begin{tabular}{|c|l|c|c|c|c|}
\hline No. & \multicolumn{1}{|c|}{ Tingkat Partisipasi } & $\begin{array}{c}\text { Alternatif } \\
\text { skor }\end{array}$ & $\begin{array}{c}\text { Jumlah } \\
\text { Pedagang } \\
\text { kaki lima } \\
\text { (orang) }\end{array}$ & $\begin{array}{c}\text { Persentase } \\
(\%)\end{array}$ & $\begin{array}{c}\text { Total } \\
\text { skor }\end{array}$ \\
\hline 1 & $\begin{array}{l}\text { Selalu membayar } \\
\text { retribusi sampah }\end{array}$ & 3 & 78 & 91,76 & 234 \\
\hline 2 & $\begin{array}{l}\text { Membayar apabila } \\
\text { dimimta pengelola }\end{array}$ & 2 & 3 & 3,53 & 6 \\
\hline 3 & Tidak bayar retribusi & 1 & 4 & 4,71 & 4 \\
\hline \multicolumn{1}{|c|}{ Jumlah } & 85 & 100 & 244 \\
\hline
\end{tabular}

Sumber : Data Primer (2018)

\section{Partisipasi Membuang Sampah Ke} TPS

Partisipasi membuang sampah ke TPS artinya apakah pedagang kaki lima (PKL) membuang sampah secara langsung ke TPS. Disini PKL secara langsung membawa sampahnya ke TPS tanpa bantuan orang lain ataupun petugas kebersihan dapat dilihat dalam tabel 3.

Tabel 3.persentase Partisipasi pedagang kaki lima Membuang Sampah Ke TPS

\begin{tabular}{|c|l|c|c|c|c|}
\hline No. & \multicolumn{1}{|c|}{ Tingkat Partisipasi } & $\begin{array}{c}\text { Alternatif } \\
\text { skor }\end{array}$ & $\begin{array}{c}\text { Jumlah } \\
\text { Pedagang } \\
\text { kaki lima } \\
\text { (orang) }\end{array}$ & $\begin{array}{c}\text { Persentase } \\
(\%)\end{array}$ & $\begin{array}{c}\text { Total } \\
\text { skor }\end{array}$ \\
\hline 1 & $\begin{array}{l}\text { Selalu membuang } \\
\text { sampah ke TPS }\end{array}$ & 3 & 34 & 40,00 & 102 \\
\hline 2 & $\begin{array}{l}\text { Kadang- kadang } \\
\text { membuang ke TPS }\end{array}$ & 2 & 6 & 7,06 & 12 \\
\hline 3 & $\begin{array}{l}\text { Sampah di tinggal di } \\
\text { tempat berjualan karena } \\
\text { ada petugas kebersihan }\end{array}$ & 1 & 45 & 52,94 & 45 \\
\hline \multicolumn{2}{|c|}{ Jumlah } & 85 & 100 & 159 \\
\hline
\end{tabular}

Sumber : Data Primer (2018)

\section{Partisipasi Menjaga Kebersihan}

\section{Tempat Berjualan}

Menjaga kebersihan tempat berjualan artinya disini apakah para pedagang kaki lima (PKL) membersihkan tempat berjualannya setiap hari dalam hal ini memperhatikan sampah dapat dilihat pada tabel 4 . 
Tabel 4. Persentase Partisipasi Pedagang Kaki Lima dalam Menjaga Kebersihan Tempat Berjualan

\begin{tabular}{|c|l|c|c|c|c|}
\hline No. & \multicolumn{1}{|c|}{ Tingkat Partisipasi } & $\begin{array}{c}\text { Alternatif } \\
\text { skor }\end{array}$ & $\begin{array}{c}\text { Jumlah } \\
\text { Pedagang } \\
\text { kaki lima } \\
\text { (orang) }\end{array}$ & $\begin{array}{c}\text { Persentase } \\
(\%)\end{array}$ & $\begin{array}{c}\text { Total } \\
\text { skor }\end{array}$ \\
\hline 1 & $\begin{array}{l}\text { Membersihkan tempat } \\
\text { berjualan setiap hari }\end{array}$ & 3 & 71 & 83,53 & 213 \\
\hline 2 & $\begin{array}{l}\text { Membersihkan saat } \\
\text { kotor saja }\end{array}$ & 2 & 11 & 12,94 & 22 \\
\hline 3 & $\begin{array}{l}\text { Hanya mengandalkan } \\
\text { petugas kebersihan saja }\end{array}$ & 1 & 3 & 3,53 & 3 \\
\hline \multicolumn{2}{|c|}{ Jumlah } & 85 & 100 & 238 \\
\hline
\end{tabular}

Sumber : Data Primer (2018)

\section{Partisipasi Memisahkan Sampah \\ Organik Dan Anorganik Sebelum membuangnya}

Partisipasi memisahkan sampah organik dan anorganik artinya disini adalah pedagang kaki lima (PKL) memisahkan antara sampah basahnya dengan sampah kering sebelum membuangnya atau tidak. Hal ini dapat di lihat pada tabel 5 .

Tabel 5. Persentase Partisipasi Pedagang Kaki Lima Yang Memisahkan Sampah Organik Dan Anorganik Sebelum Membuangnya

\begin{tabular}{|c|l|c|c|c|c|}
\hline No. & \multicolumn{1}{|c|}{ Tingkat Partisipasi } & $\begin{array}{c}\text { Alternatif } \\
\text { skor }\end{array}$ & $\begin{array}{c}\text { Jumlah } \\
\text { Pedagang } \\
\text { kaki lima } \\
\text { (orang) }\end{array}$ & $\begin{array}{c}\text { Persentase } \\
(\%)\end{array}$ & $\begin{array}{c}\text { Total } \\
\text { skor }\end{array}$ \\
\hline 1 & $\begin{array}{l}\text { Selalu memisahkan } \\
\text { sampah organik dan } \\
\text { anorganik }\end{array}$ & 3 & 20 & 23,53 & 60 \\
\hline 2 & $\begin{array}{l}\text { Memisahkan tetapi } \\
\text { masih ada yang } \\
\text { tercampur }\end{array}$ & 2 & 11 & 12,94 & 22 \\
\hline 3 & $\begin{array}{l}\text { Menyatukan semua } \\
\text { sampah }\end{array}$ & 1 & 54 & 63,53 & 54 \\
\hline \multicolumn{2}{|c|}{ Jumlah } & 85 & 100 & 136 \\
\hline
\end{tabular}

Sumber : Data Primer (2018) 
Partisipasi Membantu Pedagang Lain

Dalam Membersihkan Lingkungan Tempat Berjualan

Partisipasi membatu pedagang kaki lima lain dalam membersihkan apakah para pedagang kaki lima (PKL) membatu PKL lain mengumpulkan sampah dagangan di tempat berjualannya atau tidak, dapat dilihat pada tabel 6 . lingkungan tempat berjualan artinya Tabel 6. Persentase Partisipasi Pedagang Kaki Lima Yang Membantu Pedagang Lain Dalam Membersihkan Lingkungan Tempat Berjualan

\begin{tabular}{|c|l|c|c|c|c|}
\hline No. & \multicolumn{1}{|c|}{ Tingkat Partisipasi } & $\begin{array}{c}\text { Alternatif } \\
\text { skor }\end{array}$ & $\begin{array}{c}\text { Jumlah } \\
\text { Pedagang } \\
\text { kaki lima } \\
\text { (orang) }\end{array}$ & $\begin{array}{c}\text { Persentase } \\
(\%)\end{array}$ & $\begin{array}{c}\text { Total } \\
\text { skor }\end{array}$ \\
\hline 1 & $\begin{array}{l}\text { Selalu membatu } \\
\text { pedagang lain dalam } \\
\text { membersihkan } \\
\text { lingkungan tempat } \\
\text { berjualan }\end{array}$ & 3 & 55 & 64,71 & 165 \\
\hline 2 & $\begin{array}{l}\text { Membantu jika ada } \\
\text { yang minta tolong }\end{array}$ & 2 & 23 & 27,06 & 46 \\
\hline 3 & $\begin{array}{l}\text { Hanya mengurus } \\
\text { tempat berjualan sendiri }\end{array}$ & 1 & 7 & 8,23 & 7 \\
\hline \multicolumn{2}{|c|}{ Jumlah } & 85 & 100 & 218 \\
\hline
\end{tabular}

Sumber: Data Primer (2018)

\section{Partisipasi Memberikan Gagasan}

\section{Untuk Kegiatan Kebersihan}

Partisipasi memberikan gagasan untuk kegiatan kebersihan adalah bentuk partisipasi dimana para pedagang kaki lima (PKL) menyampaikan pendapatnya atau ide nya mengenai kebersihan pasar pada pengelola pasar atau tidak dapat dilihat pada tabel 7 . 
Tabel 7. Persentase Partisipasi Pedagang Kaki Lima Dalam Memberikan Gagasan Untuk Kegiatan Kebersihan

\begin{tabular}{|c|l|c|c|c|c|}
\hline No. & \multicolumn{1}{|c|}{ Tingkat Partisipasi } & $\begin{array}{c}\text { Alternatif } \\
\text { skor }\end{array}$ & $\begin{array}{c}\text { Jumlah } \\
\text { Pedagang } \\
\text { kaki lima } \\
\text { (orang) }\end{array}$ & $\begin{array}{c}\text { Persentase } \\
(\%)\end{array}$ & $\begin{array}{c}\text { Total } \\
\text { skor }\end{array}$ \\
\hline 1 & $\begin{array}{l}\text { Selalu meyampaikan } \\
\text { ide pada pedagang lain } \\
\text { atau pengelola pasar }\end{array}$ & 3 & 22 & 25,88 & 66 \\
\hline 2 & $\begin{array}{l}\text { Punya ide tapi tidak } \\
\text { disampaikan kepada } \\
\text { pengelola pasar }\end{array}$ & 2 & 45 & 52,94 & 90 \\
\hline 3 & $\begin{array}{l}\text { Tidak mempunyai ide/ } \\
\text { tidak peduli }\end{array}$ & 1 & 18 & 21,18 & 18 \\
\hline \multicolumn{2}{|c|}{ Jumlah } & 85 & 100 & 174 \\
\hline
\end{tabular}

Sumber : Data Primer (2018)

Partisipasi Menghadiri Rapat Atau Pertemuan Untuk Membicarakam Masalah Kebersihan

Partisipasi menghadiri rapat atau pertemuan untuk membicarakan masalah kebersihan disini apakah para

Tabel 8. Persentase Partisipasi Pedagang Kaki Lima Dalam Menghadiri Rapat Atau Pertemuan Untuk Membicarakan Masalah Kebersihan

\begin{tabular}{|c|l|c|c|c|c|}
\hline No. & \multicolumn{1}{|c|}{ Tingkat Partisipasi } & $\begin{array}{c}\text { Alternatif } \\
\text { skor }\end{array}$ & $\begin{array}{c}\text { Jumlah } \\
\text { Pedagang } \\
\text { kaki lima } \\
\text { (orang) }\end{array}$ & $\begin{array}{c}\text { Persentase } \\
(\%)\end{array}$ & $\begin{array}{c}\text { Total } \\
\text { skor }\end{array}$ \\
\hline 1 & $\begin{array}{l}\text { Selalu menghadiri rapat } \\
\text { yang diselenggarakan } \\
\text { pengelola pasar }\end{array}$ & 3 & 31 & 36,47 & 93 \\
\hline 2 & Hadir bila tidak sibuk & 2 & 9 & 10.59 & 18 \\
\hline 3 & Tidak pernah hadir & 1 & 45 & 52,94 & 45 \\
\hline \multicolumn{1}{|c|}{ Jumlah } & 85 & 100 & 156 \\
\hline
\end{tabular}

Sumber : Data Primer (2018)

a. Partisipasi Menegur Orang Lain Yang Membuang Sampah Sembarangan

Partisipasi menegur oarang lain yang membuang sampah sembarangan artinya apakah para pedagang kaki lima pedagang kaki lima (PKL) menghadiri rapat atau pertemuan yang diadakan oleh pengelola pasar yang membahas mengenai masalah kebersihan pasar. Hal ini dapat dilihat pada tabel 8 . 
Tabel 9. Persentase Partisipasi Pedagang Kaki Lima Yang Menegur Orang Lain Yang Membuang Sampah Sembarangan

\begin{tabular}{|c|l|c|c|c|c|}
\hline No. & \multicolumn{1}{|c|}{ Tingkat Partisipasi } & $\begin{array}{c}\text { Alternatif } \\
\text { skor }\end{array}$ & $\begin{array}{c}\text { Jumlah } \\
\text { Pedagang } \\
\text { kaki lima } \\
\text { (orang) }\end{array}$ & $\begin{array}{c}\text { Persentase } \\
(\%)\end{array}$ & $\begin{array}{c}\text { Total } \\
\text { skor }\end{array}$ \\
\hline 1 & $\begin{array}{l}\text { Selalu menegur bila } \\
\text { melihat orang lain } \\
\text { membuang sampah } \\
\text { sembarangan }\end{array}$ & 3 & 26 & 30,59 & 78 \\
\hline 2 & $\begin{array}{l}\text { Menegur bila } \\
\text { membuang di dekat } \\
\text { tempat berjualan }\end{array}$ & 2 & 55 & 64,71 & 110 \\
\hline 3 & Tidak peduli & 1 & 4 & 4,70 & 4 \\
\hline \multicolumn{1}{|c|}{ Jumlah } & 85 & 100 & 192 \\
\hline
\end{tabular}

Sumber : Data Primer (2018)

Partisipasi Menegur Pedagang Lain

Yang Tidak Peduli Dengan

Kebersihan Pasar

Partisipasi menegur pedagang lain yang tidak peduli dengan kebersihan pasar artinya disini apakah para pedagang kaki lima (PKL) mempunyai tingkat kepedulian terhadap sesama pedagang lain dalam hal kebersihan pasar, hal ini dapat dilihat pada tabel 10 . Tabel 10. Persentase Partisipasi PKL Yang Menegur Pedagang Lain Yang Tidak Peduli Dengan Kebersihan Pasar

\begin{tabular}{|c|l|c|c|c|c|}
\hline No. & \multicolumn{1}{|c|}{ Tingkat Partisipasi } & $\begin{array}{c}\text { Alternatif } \\
\text { skor }\end{array}$ & $\begin{array}{c}\text { Jumlah } \\
\text { Pedagang } \\
\text { kaki lima } \\
\text { (orang) }\end{array}$ & $\begin{array}{c}\text { Persentase } \\
(\%)\end{array}$ & $\begin{array}{c}\text { Total } \\
\text { skor }\end{array}$ \\
\hline 1 & $\begin{array}{l}\text { Mengajak pedagang } \\
\text { lain untuk ikut serta } \\
\text { membersihkan pasar }\end{array}$ & 3 & 64 & 75,30 & 192 \\
\hline 2 & Menegur saja & 2 & 19 & 22,35 & 38 \\
\hline 3 & Membiarkan saja & 1 & 2 & 2,35 & 2 \\
\hline \multicolumn{1}{|c|}{ Jumlah } & 85 & 100 & 232 \\
\hline
\end{tabular}

Sumber Data Primer (2018)

\section{PENUTUP}

\section{Kesimpulan}

Partisipasi pedagang kaki lima dalam pengelolaan sampah di Pasar Bawah Kota Bukittinggi dalam kategori tertinggi yaitu partisipasi dalam bentuk material yaitu membayar retribusi sampah dengan persentase $12,77 \%$ dan total skor indikator 244 hal ini terjadi karena adanya kesadaran pedagang kaki lima akan kewajibannya membayar retribusi sampah.

Indikator dalam kategori terendah yaitu partisipasi dalam bentuk tenaga yaitu memisahkan sampah organik dan 
anorganik sebelum membuangnya dengan persentasenya $7,12 \%$ dan total skor indikator 136 hal ini disebabkan oleh beberapa pedagang kaki lima yang tidak mengetahui yang mana sampah organik dan anorganik. Berdasarkan analisis deskriptif maka dapat diketahui bahwa angka indeks partisipasi pedagang kaki lima Pasar Bawah Kota Bukittinggi tergolong tinggi yaitu dengan total skor keseluruhan partisipasi 1910 yang termasuk kepada rentang partisipasi yang tergolong tinggi.

\section{Saran}

Bagi pedagang kaki lima diharapkan mampu meningkatkan lagi partisipasinya dalam pengelolaan sampah, karena kebersihan lingkungan adalah tanggungjawab bersama bukan hanya tanggungjawab dari dinas pasar atau dinas lingkungan hidup saja. diharapkan juga kepada pemerintah agar dapat menjalin kerjasama yang lebih baik lagi dengan pedagang. Berdasarkan temuan di lapangan dalam hal memisahkan sampah organik dan anorganik sebaiknya pedagang kaki lima di beri arahan atau penyuluhan oleh pemerintah agar mengetahui pentingnya memisahkan sampah organik dan anorganik supaya para pedagang tidak malas lagi memisahkan sampahnya.

\section{DAFTAR PUSTAKA}

Arikunto, S. 2008. Prosedur Penelitian Suatu Pendekatan Praktik,Ed Rivisi VI. Jakarta : Pt Rineka Cipta

Djalal, Fasli Dan Dedi Supriadi. 2001. Reformasi Pendidikan Dalam Konteks Otonomi Daerah. Jakarta : Depdiknas Bapenas Adicitakaryanusa

Sumarwanto. 2012. Pengaruh Pedagang Kaki Lima Terhadap Keserasian Ruang Publik Kota Di Semarang. Volome 1 No. 2 ISSN 2302-2752.

Tilaar, H.A.R. 2009. Kekuasaan Dan Pendidikan : Kajian Manajemen Pendidikan Nasional Dalam Pusaran Kekuasaan. Jakarta : Depdiknasbud Ri 